\title{
Activity based Mental Stress Detection and Analysis
}

\author{
V. R. Kavitha \\ Associate Professor \\ Computer Science Department \\ Dr.G.R.Damodaran College of Science
}

\begin{abstract}
Educational Data Mining is a new discipline based on the Data Mining baseline and deals with educational data. Monitoring the stress of a person continuously will help to find out the pattern of stress and intern help the physician to take the decisions easily. Current work proposes a process model to explore data from educational settings. The model is used to find out descriptive patterns and predictions that characterize learners' behaviors and achievements, domain knowledge content, assessments, and educational functionalities and applications.
\end{abstract}

\section{Keywords}

Mental Stress, Student Activity, Stress Classifier

\section{INTRODUCTION}

Analytics and data mining methodologies are used to extract useful information from large datasets. It has turned the whole environment of technological view of data during last decades. When applied to education, these methodologies are referred to as learning analytics (LA) and educational data mining (EDM).

Process discovery-discovering a process model from example behavior recorded in an event log is one of the most challenging tasks in process mining. Discovery approaches need to deal with competing quality criteria such as suitability, simplicity, accuracy, and generality. Moreover, event logs may contain low frequent behavior and tend to be far from complete, that is typically only a fraction of the possible behavior is recorded. At the same time, models need to have formal semantics in order to reason about their quality. These factors lead to the proposal of process discovery approaches in recent years. Most of these approaches are time-consuming and/or produce poor quality models. In fact, simply checking the quality of a model is already computationally challenging. By considering these factors the project is approached and a model is developed which will analyze the collected real data and came out with some findings and suggestions.

\section{BACKGROUND}

Leaving from residence for the first time and going to the college for the first time will be hard for some students. This kind of students will get home sick because they are from the comforts of parents and they feel uncomfortable in mingling with other students. These kinds of students want to isolate themselves.

The college students will have more expectations and they want to fulfill their demands on time. Transitional period to adapt to new academic environment financial pressures, interpersonal conflicts, academic and peer pressure are the origin for creation of pressure to students. The above said factors will create emotional instability intern create stress.
Stress is what you feel when you are worried or uncomfortable about something. This worry in your mind can make your body feel bad. You may feel angry, frustrated, scared, or afraid. These feeling can also lead to you having a stomachache or a headache. When you're stressed you may not feel like sleeping or eating. You also may feel cranky or have trouble paying attention at school and remembering things.

The current work is focused on two kinds of tasks.

$>$ Developing the infrastructure for stress-related data management and processing.

$>$ Different case studies from the students, collecting subjective and measuring objective stress before, during and after the group project presentations, partial exams as online multiple choice tests and regular written and oral examinations.

* In addition to the above said case studies, family background of the students is collected and based on their background different analyses are performed.

\section{LITERATURE REVIEW}

Educational data mining methods are drawn from a variety of literatures, including data mining and machine learning, psychometrics and other areas of statistics, information visualization, and computational modeling. Student modeling is a key theme in modern educational data mining, in order to do this, a researcher first needed to collect their own educational data.

To enhance the understanding of the process learning, Data mining can be used. As discussed by [1], the focus is identifying, extracting, evaluating variables related to learning process of a student. Pandey and Pal conducted a survey on the students' performance [12]. He used Bayes classification algorithm to analyse the data and came out with suggestions for the performance of a new student coming to the course. Classification techniques are applied in the literature to improve the higher education system. They studied the main area where we have concentrate to improve the performance of the students.

Data mining, also called Knowledge Discovery in Databases (KDD), is the field of discovering novel and potentially useful information from large amounts of data. It has been proposed that educational data mining methods are often different from standard data mining methods, due to the need to explicitly account for (and the opportunities to exploit) the multi-level hierarchy and non-independence in educational data [3], [8]. For this reason, it is increasingly common to see the use of models drawn from the psychometrics literature in educational data mining publications [4], [9] and [13]. 
The paper [7] deals with How different types of student behavior impact students' learning in different ways?. How variations in intelligent tutor design impact students' behavior over time? is discussed in [11]. A survey on the students' performance is conducted and discussed in [10]. The hypothesis that was stated as "Students' attitude towards attendance in class, hours spent in study on daily basis after college, students' family income, student' mother's age and mother's education are significantly related with student performance" was framed. They analyzed the information using linear regression analysis. From the study it is found that mother's education and family income are having more correlated with the academic performance of a student.

K-means clustering algorithm is used to predict students' learning activities [2]. The author applied classification techniques to evaluate students' information and performance of their end semester is discussed in [5].

There was a study conducted by Carlisle in that Stress tests are used for diagnosis of risk stratification of patients with suspected coronary artery disease (CAD), it focuses on the selection of test methods and test selection [6]. The initial cardiac stress test is the exercise stress test. It uses ECG monitoring for studying the stress. It will monitor the symptoms and Electro Cardio Gram changes associated with ischemia. In a situation where exercise is not possible then to create stress to the heart pharmacologic agents can be used. Based on the stress reading analyses are done by the physicians.

\section{Students Stress Analytics}

Adolescence is the stage; their growth is rapid in terms of physical and mental maturity. Due to this they may experience incompatibility in adjusting with their surroundings. It leads to problems. These problems will be developed psychological troubles and even leads to behavior deviations. Depending on the individuals' strength and perseverance of stress it can be positive or negative. Personality of an individual, cognitive assessment of the stress, social support will also be considered here.

The students' information are collected from various institutions and during various situations. Two methods are used to collect information from the students. First a questioner is prepared and the students are asked to fill up the questioner. This is basically for the data which is going to reflect their behavior. The questioner contains 25 questions and the sample is given in Figure 3.1. Data has been collected from students of different background and different discipline students at various situations, such as:

\section{* Before class room activity \\ * During class room activity \\ * After class room activity \\ * During project presentations \\ * During exam time \\ * Relaxation time}

Students details like family background, hosteller, day scholar information and data related to the stress in these places were also collected. $\mathrm{R}$ tool is identified to analyze the information and missing data analysis has been carried out. Duplicates were also identified and removed. The ways of collecting the information from the students are through Questionnaire. Stress level of a person will reflect the activities like creating relationship, health behaviors, academic performance, mingling with peer group members. This information are analyzed because these students are undergoing changes in their environment, adjusting/adopting to new environment, changes in the routine of activities, security issues are also considered.

Over 19500 samples were collected from different participants. K-means algorithm is used for clustering the students' information. Figure 3.2. and Figure 3.4 show the data collected from male and female students in percentile. Figure 3.3 and Figure 3.5 show the information of male and female students for selective properties.

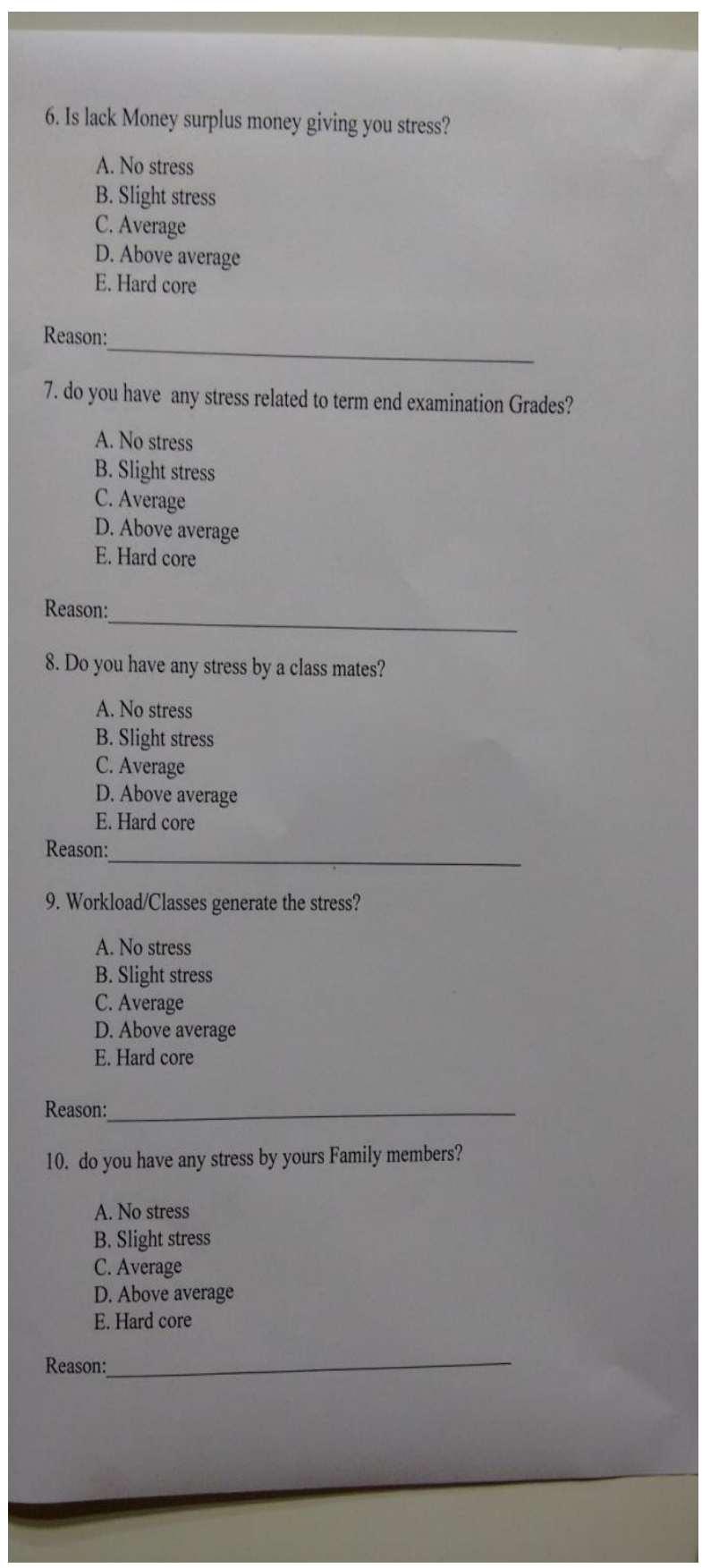

Figure 3.1 Sample Questionnaire 


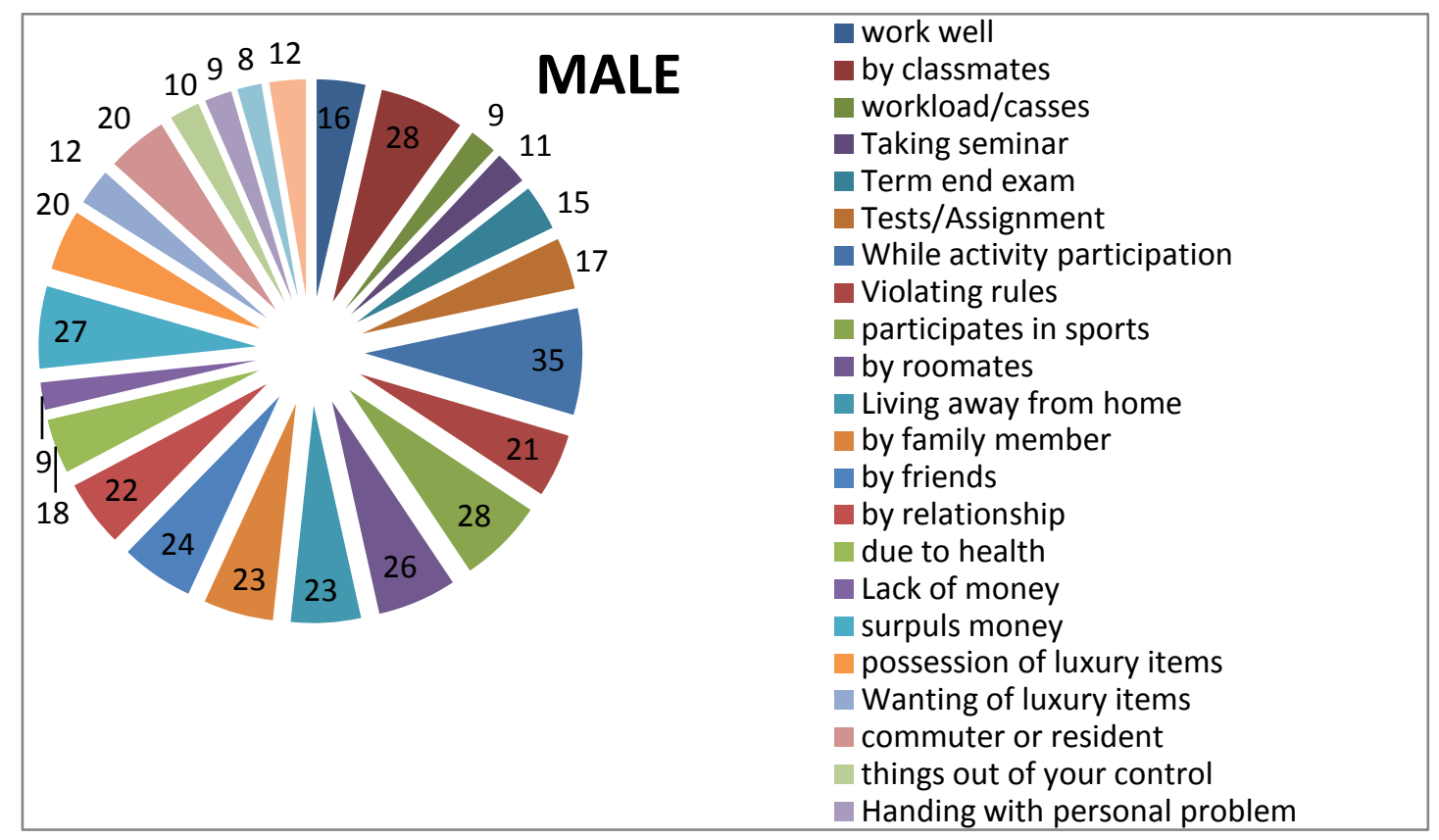

Figure 3.2 Distribution of values for Male Students

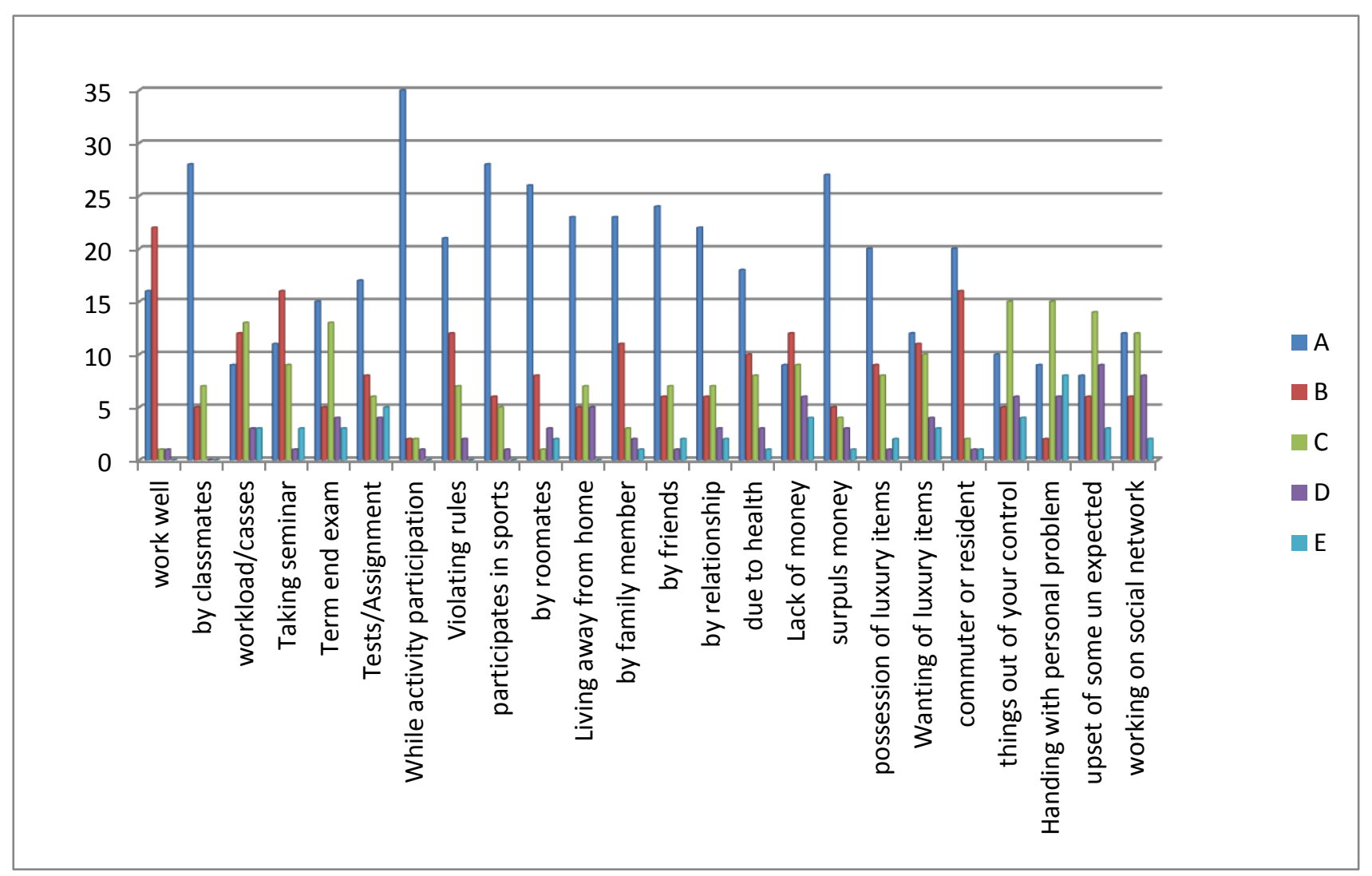

Figure 3.5 Characteristics of Male students for selected attributes 


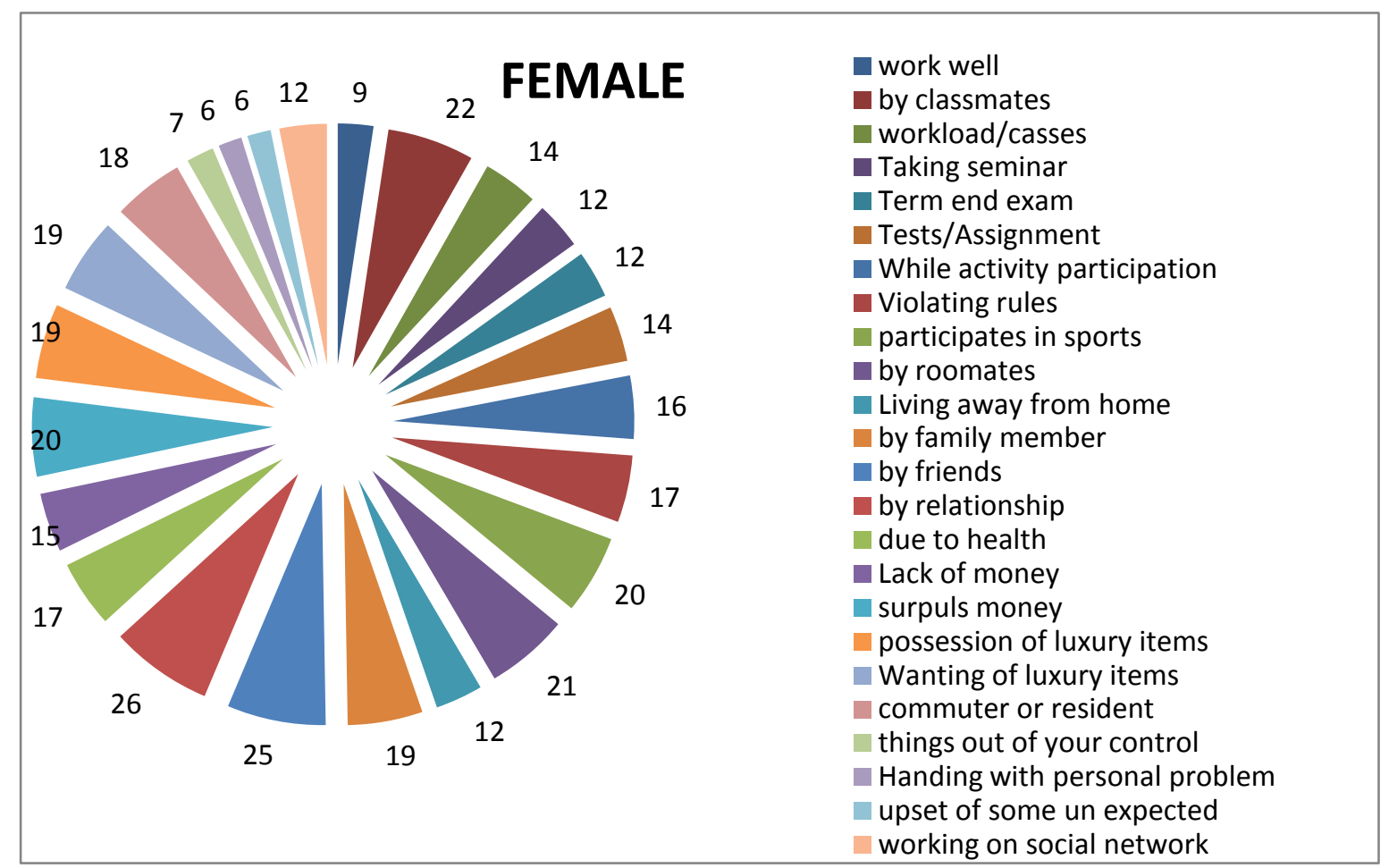

Figure 3.4 Distribution of values for Female Students

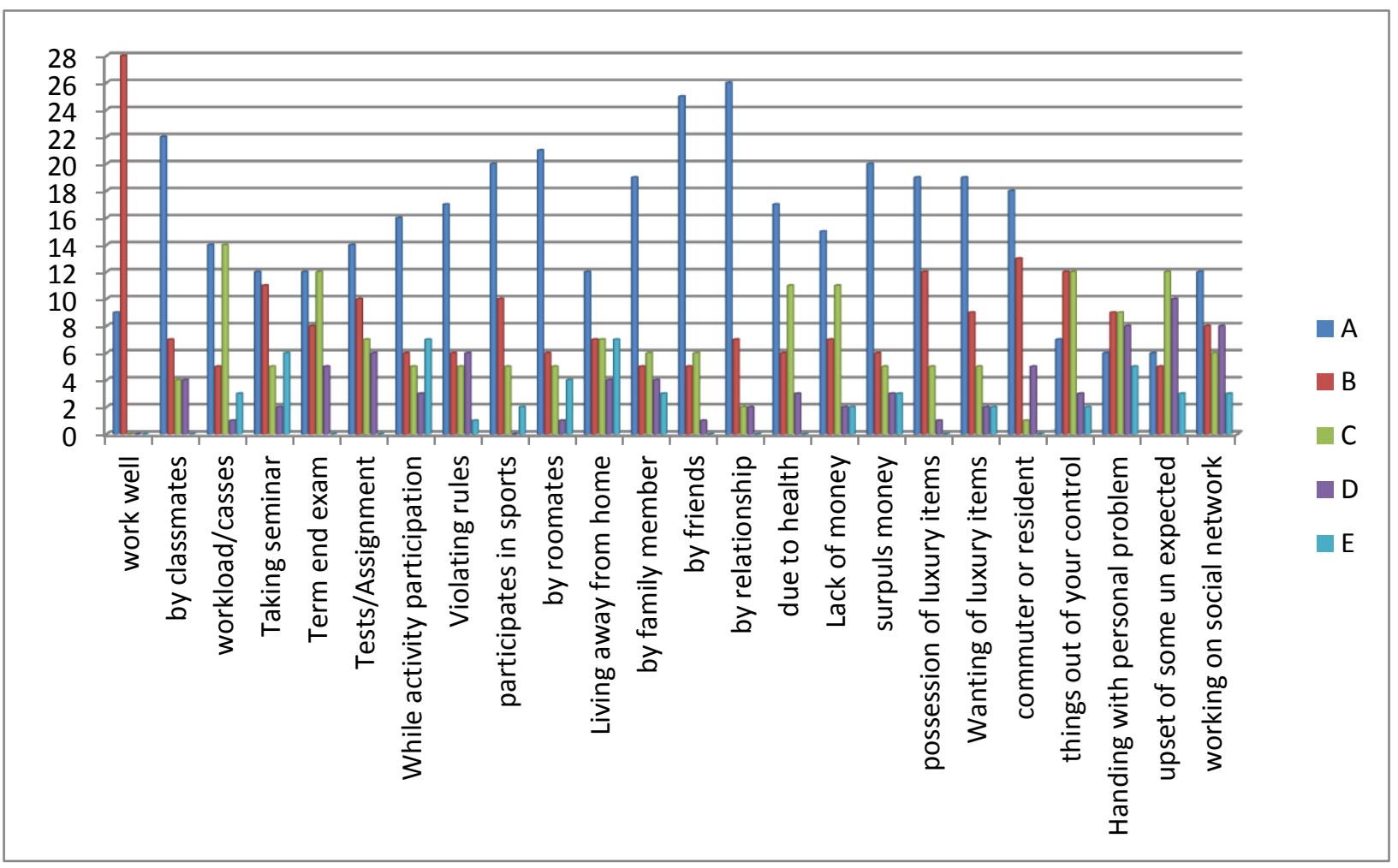

Figure 3.5 Characteristics of Female students for selected attributes 
According to the study it is found that male students are well affected by the workload and the home works given by the staff members. Female students give more important to the relationships. They are stressed because of their classmates and relationships they posses with their friends. They are able to handle the classes and works without any problem.

\section{CONCLUSION}

Based on the extensive study carried out it is found that stress play a major role in the performance of students as well as educators. Because of stress it has been identified that heart diseases, sleep difficulties, headaches and performance degradation are caused. It leads to illness and behavior disorder. The above said are short term inabilities. Long term consequences include poor academic performance, addictions, crime, and career failure are identified. Male students find difficulty while they have given more workload and when they have surplus money. Female students face problem when they are alone. The work may be extended by giving suggestion to the physician based on the information received from the individual students.

\section{ACKNOWLEDGMENTS}

This project is funded by University Grants Commission, India under Minor research project to college teachers. I thank the authorities of UGC for the opportunity given to me to do the project.

\section{REFERENCES}

[1] Alaa El-Halees, 2009, Mining Students Data to Analyze E-Learning Behavior: A Case Study.

[2] Ayesha Shaeela, Mustafa Tasleem, Raza Sattar Ahsan and M. Inayat Khan, "Data Mining Model for Higher Education System", Europen Journal of Scientific Research, Vol.43, No.1, pp.24-29, 2010

[3] Baker, R.S.J.D.,2010, Data Mining for Education. In International Encyclopedia of Education (3rd Edition), B. Mcgaw, Peterson, P., Baker Ed. Elsevier, Oxford, Uk.

[4] Barnes, T. 2005. The Q-Matrix Method: Mining Student Response Data for Knowledge. In Proceedings of the AAAI-2005 Workshop on Educational Data Mining.

[5] Bharadwaj B.K. and Pal S., 2011, "Data Mining: A Prediction for Performance Improvement Using
Classification", International Journal of Computer Science and Information Security (IJCSIS), Vol. 9, No. $4,136-140$

[6] Carlisle R., Karen M. Fitzpatrick, Jason M. Oreskovich, George T. Fredrick, 2008, "Cardiac Stress Testing for Diagnosis of Coronary Artery Disease in Adults with Acute Chest Pain”, Cardiac Stress Testing, Nov., 2008, pp: 21-29.

[7] Cocea, M., Hershkovitz, A. and Baker, R.S.J.D. 2009. The Impact of Off-Task and Gaming Behaviors on Learning: Immediate or Aggregate? In Proceedings of The $14^{\text {th }}$ International Conference on Artificial Intelligence in Education, 507-514.

[8] Dekker, G., Pechenizkiy, M. and Vleeshouwers, J., 2009, Predicting Students Drop Out: A Case Study, In Proceedings of the $2^{\text {nd }}$ International Conference on Educational Data Mining (EDM'09), 41-50.

[9] Desmarais, M.C. and Pu, X. 2005. A Bayesian Student Model Without Hidden Nodes and Its Comparison with Item Response Theory. International Journal Of Artificial Intelligence In Education 15, 291-323.

[10] Hijazi, Syed Tahir and Naqvi, S.M.M. Raza. (January 2006). 'Factors Affecting Students' Performance: ACase of Private Colleges'. Bangladesh e-Journal of Sociology: Volume 3, Number 1.

[11] Jeong, H. and Biswas, G. 2008. Mining Student Behavior Models in Learning-By-Teaching Environments. In Proceedings of the $1^{\text {st }}$ International Conference on Educational Data Mining, 127-136.

[12] Pandey, and Pal, 2011, Data Mining: A Prediction of Performer or Underperformer Using Classification, (IJCSIT) International Journal of Computer Science and Information Technology, Vol. 2(2), 686-690.

[13] Pavlik, P., Cen, H. and Koedinger, K.R. 2009. Learning Factors Transfer Analysis: Using Learning Curve Analysis to Automatically Generate Domain Models. In Proceedings of the 2nd International Conference on Educational Data Mining, 121-130. 